\title{
La relación entre arte y política como un entramado: la poética de Edgardo Antonio Vigo
}

\section{The relationship between art and politics as a weave: the poetics of Edgardo Antonio Vigo}

\author{
Ana Liza Bugnone \\ Centro de Estudios de Teoría y Crítica Literaria / Instituto de Investigaciones en Humanidades y \\ Ciencias Sociales (UNLP - CONICET). Facultad de Humanidades y Ciencias de la Educación. \\ Universidad Nacional de La Plata. \\ anabugnone@gmail.com
}

Recibido: 12 de abril de 2011

Aprobado: 24 de mayo de 2011

\section{Resumen}

En este trabajo se analiza la relación entre arte y política a través de la poética del artista Edgardo Antonio Vigo en una época convulsionada en términos artísticos y políticos: las décadas de 1960 y 1970. Más que a un nexo en el que el contexto político determina y encuadra la politicidad del arte, se apela a una interpretación en la que esa vinculación es múltiple, compleja e inestable, lo que configura un entramado.

Para ello se analizan tres zonas de su obra -la poesía visual, las acciones en el espacio público y la utilización del lenguaje judicial-administrativo en sus producciones-, pues se considera que es posible, a partir de allí, interpretar aspectos centrales de su poética política.

Palabras Clave: Arte, política, espacio público, poesía, lenguaje.

Bugnone, A. 2011: La relación entre arte y política como un entramado: la poética de Edgardo Antonio Vigo. Arte, Individuo y Sociedad, 23 (2), 109-119

\begin{abstract}
In this paper we analyze the relationship between art and politics through the poetics of the artist Edgardo Antonio Vigo in a time artistic and politically convulsed: the 1960s and 1970s. Rather than to a link in which the political context determines and frames art's politicity, we appeal to an interpretation in which that connection is multiple, complex and unstable, building a weave.

In order to do that we analyze three zones of his work - visual poetry, actions in public space and the use of legal language in his works - since we consider they make it possible to interpret central aspects of his political poetics.
\end{abstract}

Key Words: Art, politics, public space, poetry, language.

Bugnone, A. 2011: The relationship between art and politics as a weave: the poetics of Edgardo Antonio Vigo. Arte, Individuo y Sociedad, 23 (2), 109-119

Sumario: 1. Introducción, 2. Arte y politización, 3. Tres zonas de una poética política, 4. Reflexiones finales. Referencias 


\section{Introducción}

Cuando nos preguntamos de qué modos pueden vincularse arte y política resuena, en general, la idea de que el contexto político condiciona o determina la politicidad de las obras de arte y que esa politicidad depende y se expresa a través del tema de la obra. Así, una pintura o acción que refiera a algún hecho o personaje político, sería el modelo de arte político. Puede, sin embargo, complejizarse esa idea y plantearse que la relación entre ambos no es lineal ni estructurada, sino más bien que funciona como un entramado, en el que hay múltiples y diversas conexiones que se dan no sólo por la incorporación de temáticas políticas en las obras de arte, sino también por la forma y materialidad de las mismas. Partiendo de esta idea, resulta pertinente analizar un caso específico, el del artista argentino Edgardo Antonio Vigo (1928 - 1997), un neovanguardista que construyó una poética disruptiva en el contexto de radicalización política de los años ' 60 y '70.

Los cruces entre esa situación social general y la especificidad del campo artístico, ofrecen posibilidades para el análisis de la relación entre arte y política en ese período particular. Se considerarán tres zonas de la producción artística de Vigo sobre las que se han generado hipótesis para pensar ese cruce: la poesía visual, las acciones artísticas en el espacio público urbano y el uso del lenguaje judicial-administrativo en obras de arte. De este modo, se trata de reflexiones preliminares basadas en el trabajo empírico que se ha realizado sobre su obra, pero que no constituyen ideas acabadas, sino más bien, preguntas abiertas e inconclusas.

\section{Arte y politización}

Las representaciones de la cultura de las décadas de los ' 60 y ' 70 se constituyeron en una confluencia de acontecimientos y discursos que van desde la transformación de diversos ámbitos de la sociedad y la cultura hasta el uso de la violencia política. La situación histórica estaba marcada por cambios culturales generacionales, que incluían la liberalización de las relaciones y formas sociales, de la sexualidad, el juvenilismo, los movimientos feministas, hippies y contestatarios en general, y allí la obra de Vigo construyó también una nueva mirada del mundo estableciendo contradicciones con el carácter social dominante de la época (Williams 2003), a través de obras y discursos que cuestionan los valores, las formas de vida, la represión y la reproducción sociales. En Argentina, los gobiernos dictatoriales y semi-democráticos instalados en el poder desde el golpe de estado de 1955, marcaron la política local represiva con mayor o menor intensidad hasta 1973 y luego desde 1975 hasta la llegada de la democracia en 1983. Frente a estos gobiernos, distintos actores sociales, como organizaciones políticas, estudiantiles, obreras, periodistas, artistas intentaron cambiar el curso represivo de la política, y en algunos casos, del "sistema" en general.

Se desarrolló así un proceso de progresiva politización social en el que una ética del compromiso social y político emergía como imperativo para intelectuales, artistas y actores sociales en general, y Vigo -como otros artistas de la época- se vinculó con la política a través de la tematización de los acontecimientos políticos más relevantes del período a nivel nacional e internacional (entre ellos, la figura de Ernesto "Che" 
Guevara, la Revolución Cubana, la guerra de Vietnam y otros locales, como el Cordobazo $^{1}$ o la masacre de Trelew $^{2}$ ), así como acercándose ideológicamente a organizaciones políticas y cruzando su discurso con la ideología de la nueva izquierda. Pero la relación entre el arte y la política también se dio de un modo menos explícito, en tanto no se trató de una dependencia temática. Así, podemos identificar en su obra lo político del arte como generador de un desequilibrio (disimetría, disidencia, disenso) cuyo tenor conviene calificar de político en tanto implicaba modos de abandonar, reemplazar o perturbar el orden de las cosas y las compartimentaciones y ubicaciones de sujetos, identidades y funciones (Rancière 2010). Se trata de la tensión con los sentidos disponibles, "normales" o dominantes de la sociedad que puede identificarse a través del análisis de sus producciones.

Nos referimos con esto a la potencialidad desestabilizante que emana de obras de arte que, desencajando las reglas del uso del espacio y de los lenguajes, puede configurar condiciones para la emergencia de nuevas miradas del mundo. Al mismo tiempo, también incorpora elementos del arte político pedagógico, es decir aquél que pretende establecer una relación directa entre la obra y la politización de la sociedad. Puede sostenerse que Vigo no se transforma en un artista panfletario o didactista, un promotor de propaganda política que intenta convencer con un mensaje claro y directo sobre las bondades de un modelo político. Sino que, al tiempo que hace referencia a alguna cuestión de la política, conserva una poética opaca, que produce configuraciones propias que no es posible decodificar según discursos disponibles. En la mayoría de sus obras, acciones, objetos o poesías más explícitamente políticas se conservan elementos de este tenor.

Este entramado dará cuenta de la politicidad de sus prácticas en el marco de un proceso de politización general de la sociedad. Estas dos dimensiones, la vinculación con los acontecimientos políticos y lo político del arte, serán, así, parte fundamental de la poética desarrollada por Vigo.

\section{Tres zonas de una poética política}

Para reflexionar sobre la idea de entramado de arte y política en la poética de Vigo, se atenderá a tres tipos de producciones. En primer lugar, la realización de poesía visual por parte del artista y su publicación en revistas -las más destacadas son las que él mismo dirigía, Diagonal Cero y Hexágono- presentaba una disrupción en el lenguaje, utilizando letras, números, imágenes, signos, líneas superpuestos. A veces, además, intervenía el papel con cortes o pliegues, sobre los que el lector debía intervenir para terminar de componer la poesía. La utilización de imágenes y colores junto a las letras y números, descolocan cualquier lectura progresiva y estable de la poesía (Fig.1) 


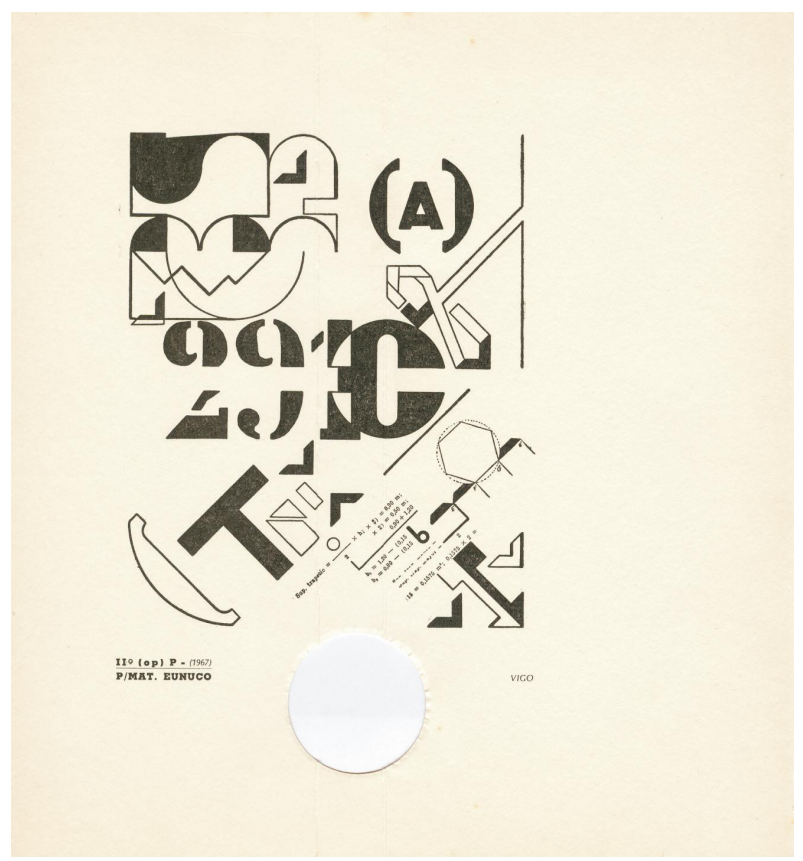

Figura 1. E. A. Vigo, P/Mat. Eunuco, 1967. Archivo CAEV.

Estas composiciones no conforman un sistema ni responden a la estructura de la literatura ni de la matemática. Emerge, así una politicidad en la objetualización del significante o del número, reducido a materia visible, y vinculada con la alegoría -en el sentido que le otorga Benjamin (1990) -, en tanto están hechas de fragmentos no correlativos con una totalidad significativa, y carecen de una teleología que proyecte de antemano los resultados de la experiencia estética. Esta fragmentación descoloca la idea de significado único y verdadero, para dar lugar a palabras, imágenes y signos imposibles de remitir a un todo. Genera, de este modo una poesía que no puede leerse, desarticulada de las normas habituales de interpretación y decodificación y de un horizonte cultural de organización e intercambio compartidos. Apela, además -con un interés propio de las neovanguardias- a un público activo que se desenvuelva como participante en la construcción de la obra: interpretando la constitución de una obra no-codificada, desplegando papeles, mirando por agujeros. Intenta generar, así, un cambio de roles, o al menos una puesta en cuestión de las ubicaciones de los sujetos activos y pasivos en la construcción y recepción de una obra de arte. Puede establecerse aquí un paralelo entre la obra de Vigo y la del poeta catalán Joan Brossa (1919 - 1990) en relación con la poesía visual. Si bien sus itinerarios artísticos han sido divergentes (Vigo parte de la plástica y Brossa, de la poesía), interesa señalar el interés de ambos por renovar el lenguaje normal o naturalizado, tanto de la plástica como de la poesía. Asimismo, la utilización de objetos cotidianos, transformados en otros objetos artísticos y la ironía como medio en la producción artística, indican 
un camino común. En ambos casos, las formas de sus obras no están exentas de politicidad. La diagramación de poesías visuales compuestas por letras y otras imágenes, en ambos casos, interpela a la práctica común de la lectura y a la percepción normal de una obra de arte. Ejemplos de ello en el caso de Brossa son "Cap de bou", una letra A pata arriba, o "Desmuntatge", una letra A y abajo su descomposición en tres partes. Cabe destacar, además que esta conexión que hoy puede analizarse entre ambos artistas existió décadas atrás: en 1965 la revista que Vigo dirigía y editaba, Diagonal Cero, dedicó su número 15/16 a Joan Brossa. Allí publicó sus poesías con una introducción de Marcos Ricardo Barnatán.

Vigo, al mismo tiempo que desestructura el lenguaje en la poesía visual, incluye aspectos de la vida política de alto impacto en la sociedad de ese momento, de modo que son frecuentes las menciones a la opresión del "sistema", la pobreza del "tercer mundo", así como los acontecimientos políticos locales e internacionales mencionados arriba. Pero estas inclusiones, no implicaron una mera tematización política, sino que además, descolocan a un lector que si bien conoce esos hechos, se conecta con obras que interpelan su propia subjetividad socio-cultural. Esta característica también puede verse en el caso de Brossa, por ejemplo, la poesía visual "Espanya 75" forma una cruz esvástica con bastos y espadas de la baraja española sin otro texto o imagen agregados, apelando al significado particular del símbolo en su país, pero evitando referencias explicativas.

El segundo aspecto de la obra de este artista que mencionaremos son los Señalamientos. Se trata de una serie de acciones que consistían en destacar algún hecho u objeto artísticamente, algunas de las cuales se realizaron en el espacio público urbano. A tono con la época, vemos ejemplos de acciones en el espacio público en otras partes del mundo, como las desarrolladas por Daniel Buren a través del uso del popular motivo francés de las rayas en 1968. Entre las acciones realizadas por Vigo, llevó a cabo el señalamiento de un semáforo en una esquina de la ciudad de La Plata donde convergen avenidas y organismos de control público, llamando a realizar, a través de un manifiesto, una experiencia estética de su contemplación, desubicando la función del semáforo, del artista (que no "produce" la obra y que además, ni siquiera concurrió), y de un público convocado a convertir ese artefacto en un objeto artístico. Otro señalamiento en el espacio público consistió en una invitación a través de tres tarjetas a orinar, luego defecar en una esquina céntrica de la ciudad y finalmente, experimentar un goce estético, entrando en "trance poético", mientras se recorre un camino indicado en la última tarjeta. La parodia de una votación en la vía pública en plena dictadura de Onganía y la filmación del monumento de Mitre ${ }^{3}$, ofreciendo a la "ciudadanía" a participar del señalamiento con una invitación que sancionaba lo obsoleto de los viejos hábitos y hábitats, son otros dos casos de acciones en el espacio público de este artista (Fig. 2) 


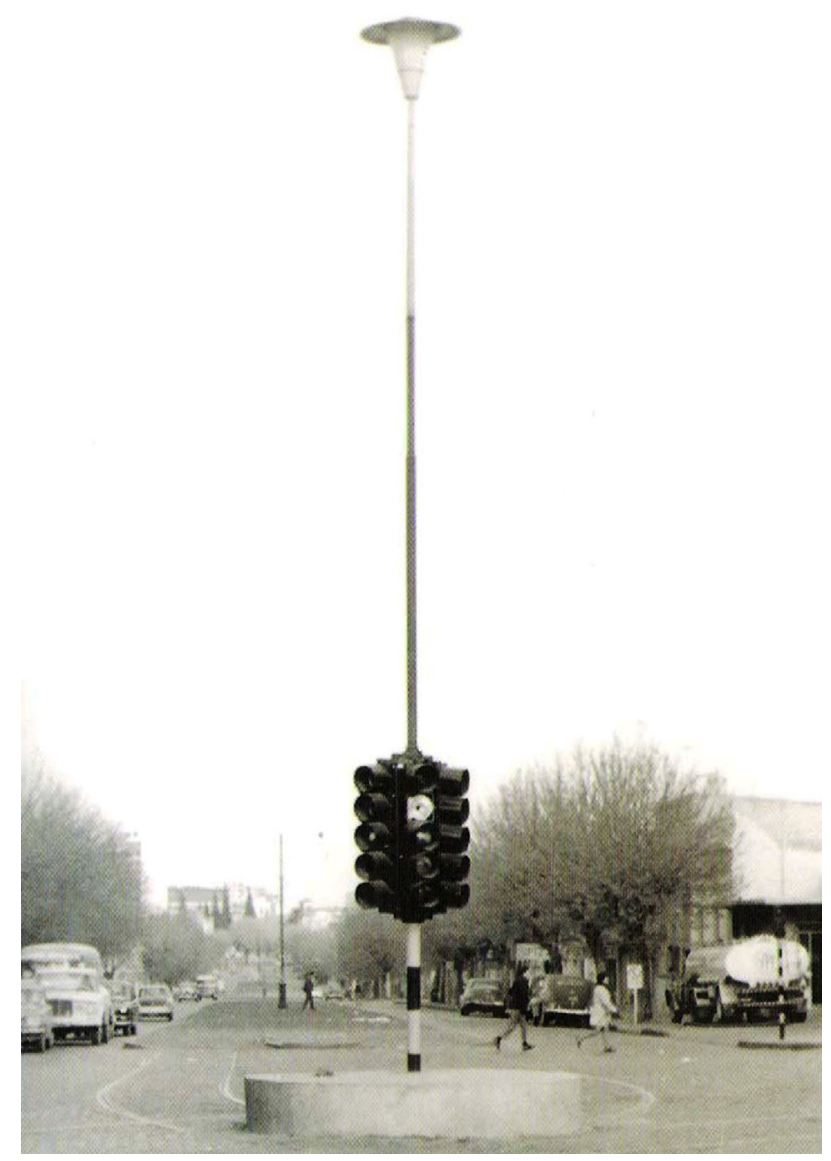

Figura 2. E. A. Vigo, Señalamiento "Manojo de semáforos", 1968. Archivo CAEV

Una de las particularidades de estas y otras acciones en el espacio público es que el autor proyectó su ubicación en ese espacio, a diferencia de otras acciones artísticas que sólo son trasladadas del museo o la galería. Es decir que apuntaba a la vinculación con un público más amplio que el de los sitios específicos del campo artístico. Otro de los aspectos destacados es que en la construcción de estas acciones utilizó elementos urbanos, como el semáforo, el monumento, la vereda y el mapa. La incorporación de objetos existentes en las obras de arte ya venía siendo utilizada desde hacía décadas, cuyo resultado había sido un cuestionamiento radical de los roles del artista como autor y de la obra como pieza artística (encontramos el antecedente principal en los ready-made de Duchamp), y en este caso, Vigo retoma esa línea al emplear elementos tales como un monumentos, un semáforo, una vereda con la construcción de sus señalamientos, y expresa públicamente la intención de generar un extrañamiento en relación con esos objetos, desencajarlos de su cotidianeidad 
corriente. Más allá de esto, interesa destacar que esos objetos, una vez incorporados a la acción artística, se ponen a disposición del público, transformados en otra cosa. Vigo convierte un monumento de representación cívica, como es el de Mitre, en una acción que convoca a la "ciudadanía" a vivir una experiencia desacralizada de su carga histórica, y esto, en plena dictadura militar, cuyos usos de los espacios y monumentos históricos se dirigen a la búsqueda de legitimidad frente a una población desencantada. Asimismo, con el uso del semáforo y la vereda en una acción artística, Vigo separa sus funciones primordiales, en un caso, de organización, en el otro, de circulación, para contradecirlas, aún sin forzar su funcionamiento normal (el semáforo no fue modificado ni la vereda obstruida). Todo ello conduce a reflexionar sobre a la politicidad de estas acciones como prácticas emancipatorias, asociadas a un espacio público y político pluricéntrico y heterogéneo (Expósito 2001). Más allá de que el tema de las obras no sea explícitamente político, su politicidad se presenta en la posibilidad de franquear las barreras que regimentan el uso represivo del espacio público, proscrito para la expresión política y popular. Cuando contradice ese orden, al mismo tiempo está haciendo evidente esa limitación y propone un modo de actuar sobre el mundo, una posibilidad de relación entre subjetividades divergentes de las dominantes en el espacio público codificado.

Los Señalamientos a partir de la intervención simbólica y material sobre el espacio público sugirieron una contra-construcción del espacio al distorsionar su uso común y cotidiano, oponiendo a las lógicas que determinan los usos y funciones del espacio público y a las reglas que condicionan la producción artística, un dislocamiento y una ampliación de los márgenes de acción y representación posibles. En este sentido, posibilitaron la operación simbólica de la resistencia que forma parte de la relación compleja entre hegemonía y emergencia de nuevas representaciones.

Esta contra-significación del espacio público implicó también una referencia simbólica a lo público como popular, es decir, vinculado a la idea tanto de pueblo en general -el que usualmente no accede a las expresiones de la alta cultura elitista-, como del pueblo peronista proscripto por los sucesivos gobiernos desde 1955. Ubicando a propósito las acciones en el espacio público, haciendo uso del mismo y tomando elementos urbanos como parte del señalamiento, Vigo pone en cuestión también la propia espacialización dictatorial que se apodera de los espacios y sus elementos en una lógica anti-popular. Hace evidente, así, la contradicción dictadura/ pueblo y al mismo tiempo, la contradice.

Las prácticas artísticas, al emplazarse en el espacio público, disrumpen el orden que prohíbe su utilización para la expresión libre $\mathrm{y}$, al mismo tiempo, colocan un arte que contacta con las rutinas cotidianas en otro espacio, afuera de las galerías y museos (donde, si bien había un proceso de incorporación de acciones vanguardistas, esas prácticas cotidianas no tienen lugar por tratarse de un ámbito diferenciado). Este proceso de doble ruptura, debe leerse especialmente en el contexto histórico tanto del campo artístico como de lo social-político en general. En relación al primero, si bien habían tenido lugar las primeras acciones artísticas en el espacio público en señal de protesta contra el régimen canónico de consagración de artistas y circulación de obras, situados en la ciudad de La Plata, las acciones analizadas, aparecen entre las primeras que cruzan ese borde que limita lo habilitado y lo no habilitado por la 
institución arte en esa década. En algunos señalamientos, a través de la búsqueda de conmoción del régimen de lo sensible, Vigo no apela directamente a politizar la práctica habitual generando "conciencia" (social, política), pero propone interpelar la vivencia acostumbrada. En otros, aparecen mencionados hechos políticos y son éstos los señalados. Algunos casos de éstos son las múltiples referencias que hace el artista a la "Masacre de Trelew", tal como lo hace en el Señalamiento 11, aludiendo a ese hecho y colocando en el reverso una imagen cortada y calada en el ojo de Ernesto "Che" Guevara, figura referente de la juventud militante de los años '60 y '70 (fig. 3 a y b). A través de sus acciones, Vigo participa del proceso de radicalización que se estaba viviendo, pero conservando en casi todos los casos rasgos materiales de la serie, como la flecha que señala y la utilización de materiales no convencionales, así como -salvo en algunas excepciones- un mensaje que tiene algo velado y que el propio espectador deberá interpretar, esquivando así el tipo de mensaje propagandístico.

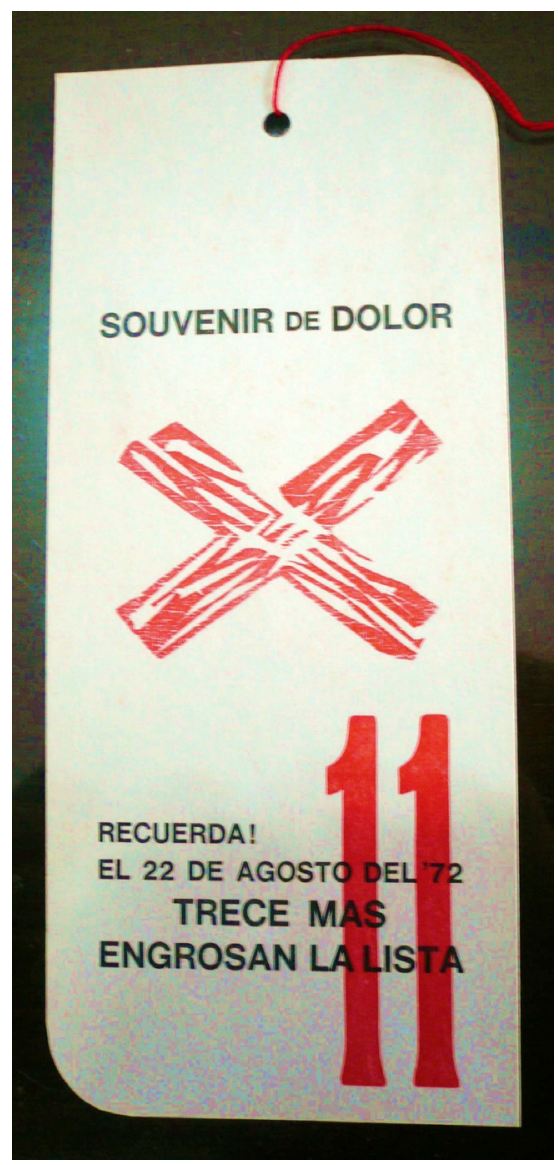

Figura 3a. E. A. Vigo Señalamiento 11 Souvenir del dolor, 1972. 


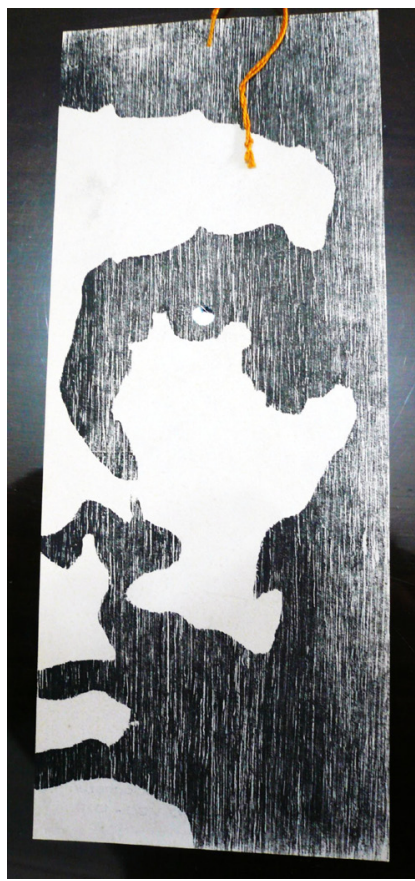

Figura 3b. E. A. Vigo Señalamiento 11 Souvenir del dolor (reverso), 1972.

La utilización del lenguaje judicial-administrativo en algunas de sus obras y acciones es el tercer aspecto a analizar. Vigo usó sellos y frases típicos de este lenguaje y más allá de que esto pueda remitirse a su trabajo como empleado de los Tribunales, esta utilización merece ser analizada (Fig. 4).

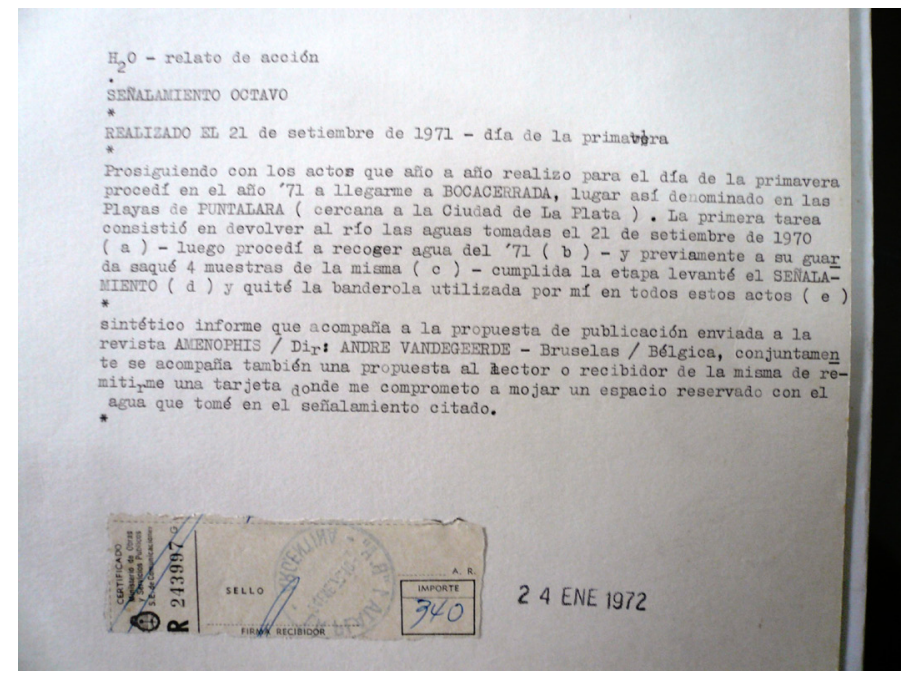

Figura 4. E. A. Vigo, Señalamiento Octavo, 1972. Archivo CAEV. 
En la poética de Vigo, el lenguaje judicial-administrativo puesto a formar parte de acciones u obras implica una operación de traslación y des-ubicación, de modo que un lenguaje apropiado para un ámbito específico -burocratizado e identificado con el orden, la ley y la sanción- es desplazado a la obra de arte. Este movimiento ubica en un lugar vinculado a la creatividad y la libertad una marca que no le pertenece, pero que, además es contradictoria con aquél: es la repetición de una forma en un espacio extraño lo que la convierte en diferencia. En la des-ubicación hay una desestructuración de lo propio del circuito judicial formal y una apuesta a la circulación en un ámbito ajeno. Publicita, así, un lenguaje restringido, desacralizándolo y haciéndolo común; pero también estetizando, lo que tiene una identificación pragmática bien ajena a lo contemplable, lo bello. Puede leerse allí, también, una vinculación con la "vida", como un intento más por desbaratar las barreras que la separan del arte, intención postulada tanto por las vanguardias históricas, como por las neovanguardias de posguerra. Vigo hizo especial hincapié a través de sus ensayos y en la formulación de obras en la idea de "participación" del público. Puede entenderse, entonces, que esta operatoria de des-ubicación, al incorporar algo típico de otra esfera, que es en la que el mismo artista se desempeñaba como empleado, integra en el arte materiales, restos y marcas de un mundo operado por empleados judiciales y dirigido por jueces y legisladores.

Al desacralizar el lenguaje judicial, también lo hace con aquéllos a quienes representa: la corporación judicial de un sistema aristocratizante. Lo populariza, en el doble sentido de hacerlo conocer (al público) y de verterlo al pueblo, poniéndolo a circular en señalamientos en un espacio accesible, en objetos, en poesías visuales. Lo político de esta operación está en la des-ubicación que rompe con un punto material y simbólico del orden social naturalizado, al descolocar el lenguaje de su espacio normal, restringido y excluyente, y ponerlo a disposición de otros a través de una materialidad específica, la obra de arte.

\section{Reflexiones finales}

En esta poética política, el arte desarrolló su politicidad mediante prácticas históricas particulares, en consonancia con algunos de los cambios sociales y políticos que implicaron un proceso de politización y radicalización social, pero también por energías surgidas en el interior del campo. Para el contexto histórico que nos ocupa, el modo en que esa politicidad tomó forma consistió en un complejo entramado de relaciones con la política.

Las rupturas de su obra con aspectos del carácter social dominante de la época se traducen en intentos de movilizar la experiencia sensible hacia la emergencia de situaciones que no encajen en la totalidad significativa común. Sus producciones artísticas, constituyeron una poética que actuaba en dos niveles: en el primero, contradecía algunos cánones más tradicionales del campo del arte, retomando las prácticas de las vanguardias históricas y llevando a cabo acciones, producciones y discursos que desafiaban las reglas del mismo; en otro nivel se ubica su relación con el carácter social dominante, a través del cual sus producciones se presentan ya no como reflejo, sino en contraste con el mismo. En estas últimas relaciones, si bien pueden identifi- 
carse analíticamente con los dos modos predominantes referidos arriba (la política y lo político), éstos actuaban en vinculación compleja y en muchos casos superpuesta. Así, puede afirmarse que en la práctica artística y la poética de Vigo convivían el arte político, es decir aquél en el que la política es el tema de la obra, y que pretende, pedagógicamente, enseñar algo acerca del mundo para lograr una toma de conciencia en el público, y lo político del arte en su confrontación con el carácter social dominante del período. De este modo, la poética de Vigo, además de vincularse con los sentidos políticos previamente constituidos en otros campos, es decir, las ideologías en disputa, también se constituyó como uno de los territorios donde el desequilibrio entre sus acciones y las convenciones del orden social tuvo un carácter que puede calificarse como político.

\section{Agradecimientos:}

Agradezco al Centro de Arte Experimental Vigo por haber permitido el uso de su vasto archivo para realizar este trabajo. Agradezco también a Miguel Dalmaroni por las sugerencias que realizó sobre el borrador del mismo.

Este artículo es el resultado de la investigación que llevo a cabo en el marco de mi tesis doctoral en la Universidad Nacional de La Plata, financiado por una beca de postgrado del Consejo Nacional de Investigaciones Científicas y Técnicas (CONICET).

\section{Referencias}

Benjamin, W. (1990). El origen del drama barroco alemán. Madrid: Taurus. (Ed. Original 1928).

Expósito, M. (2001). Vivir en un tiempo y un lugar y (acaso) representar nuestra lucha. Para introducir (y problematizar) la relación entre esfera pública y practicas antagonistas. En: P. Blanco, J. Carrillo, J. Claramonte y M. Expósito (Eds.): Modos de hacer. Arte crítico, esfera pública y acción directa. (págs. 217-226). Salamanca: Ediciones de la Universidad de Salamanca.

Rancière, J. (2010). El espectador emancipado. Buenos Aires: Manantial.

Williams, R. (2003). La larga revolución. Buenos Aires: Nueva Visión. (Ed. Original 1961).

\section{Notas}

1. El "Cordobazo" fue una rebelión popular desencadenada en la ciudad de Córdoba, Argentina, en mayo de 1969, donde confluyeron obreros, estudiantes y ciudadanos en general, ante el represivo gobierno de Juan Carlos Onganía.

2. La "Masacre de Trelew" fue el asesinato de 16 presos políticos, militantes de organizaciones de izquierda, el 22 de agosto de 1972, durante la dictadura de Alejandro A. Lanusse.

3. Bartolomé Mitre fue un historiador, estadista y presidente argentino entre 1862 y 1868 . Con sus escritos, forjó la historia oficial de su país, relatando los hechos que llevaron a la gloria a héroes de la patria, como José de San Martín y Manuel Belgrano. 